\title{
CONGENITAL DEFECT OF THE SCALP: AN INFANT WITH A BULLOUS LESION AT BIRTH
}

\author{
BY \\ SIMON YUDKIN, PH.D., M.B., M.R.C.P., D.C.H. \\ Nuffield Fellow in Child Health. (From the Mothers' Hospital, London)
}

The following case seems worth recording because of the light it may throw on the etiology of this comparatively rare condition.

\section{Case History}

S. P. was born on April 28, 1947. She was the first child of normal parents. Pregnancy and labour were normal, and the birth weight was $7 \mathrm{lb} .13 \frac{1}{2} \mathrm{oz}$.

At birth there was a flaccid, oval, bullous swelling measuring $1 \frac{1}{8}$ in. by $\frac{5}{8}$ in. over the anterior inferior end of the left parietal bone (Plate II). The wall of the swelling was translucent, purplish in colour, and devoid of hair and sweat glands. The thin wall arose directly from the surrounding skin, which was quite normal: a small amount of serous fluid was oozing from a tiny puckered area in the wall. The floor of the lesion consisted of the parietal bone, and there was no evidence of communication between the lesion and the cranial cavity. About half an inch in front of this main lesion was a small area $\frac{1}{4}$ in. in diameter where the skin appendages were absent but the scalp was of normal thickness. There were two tiny similar areas at the posterior end of the main lesion. A radiograph of the skull showed no bony defect.

The child was otherwise quite well and there were no other congenital abnormalities. The mother's Wassermann reaction was negative; there was no consanguinity of the parents, and no history of any similar condition in any member of the family.

The oozing stopped after two days and the bulla became slightly more tense. When the child was seen at the age of four months most of the fluid had been absorbed and the wall was thickened. The small lesions were unchanged.

\section{Comment}

Of congenital defects of the skin, by far the largest proportion occur in the scalp. (Anderson and Novy, 1942). They have been variously attributed to trauma, amniotic adhesions, or developmental defect. The usual appearance at birth varies from a punched out, granulating ulcer to a thin cicatrix with no skin appendages (Abt, 1917). The appearance seen in the present case has not so far been recorded in an infant at birth although Ingalls in
1933 described five embryos of from 15 to $187 \mathrm{~mm}$. in length, each with a bleb or bullous area in the dorsal midline of the head. Ingalls pointed out that the scalp is a region of marked embryological activity and that the presence of occasional faults in development was therefore not surprising. He suggested that the thin covering of the lesions he described might easily ulcerate and would account for the usual appearance at birth. In spite of the position of the lesion here described it seems likely that it represents a condition such as that described by Ingalls, although, however, it remained unbroken throughout pregnancy and the birth process.

Apart from the light thrown on the etiology of congenital defects of the scalp by this case there are other features of these defects that favour a developmental origin.

1. Amniotic adhesions are practically never found, and when present cannot always be related to the site of the defect (see Greig, 1931 for details).

2. Congenital defects of the scalp are usually in the midline, and if not, are usually symmetrical.

3. The history of birth trauma is usually very vague and could not account for the presence of healed or healing lesions at birth.

4. They are frequently multiple (Yudkin, 1947).

5. The whole thickness of the scalp and sometimes the underlying bone are affected.

6. Other developmental defects are fairly frequently present (Greig, 1931; Anderson and Novy, 1942). These include hydrocephalus, cranial meningocele, harelip, and posterior rachischisis.

7. The condition has occasionally occurred in more than one member of a family (Campbell, 1826; Mackay, personal communication).

I should like to thank Dr. H. M. M. Mackay for permission to publish this case.

\section{REFERENCES}

Abt, I. (1917). Amer. J. Dis. Child., 14, 113.

Anderson, N. P., and Novy, F. G., Jr. (1942). Arch. Derm. Syph., Chicago, 46, 257.

Campbell, W. (1826). Fdinb. J. med. Sci., 2, 82. (Quoted by Greig, 1931.)

Greig, D. M. (1931). Ibid., 38, 341.

Ingalls, N. W. (1933). Amer. J. Obstet. Gynec., 25, 861. Yudkin, S. (1947). Proc. roy. Soc. Med., 40, 533. 
CONGENITAL DEFECT. OF THE SCALP BY SIMON YUDKIN

Infant, showing bullous lesion.

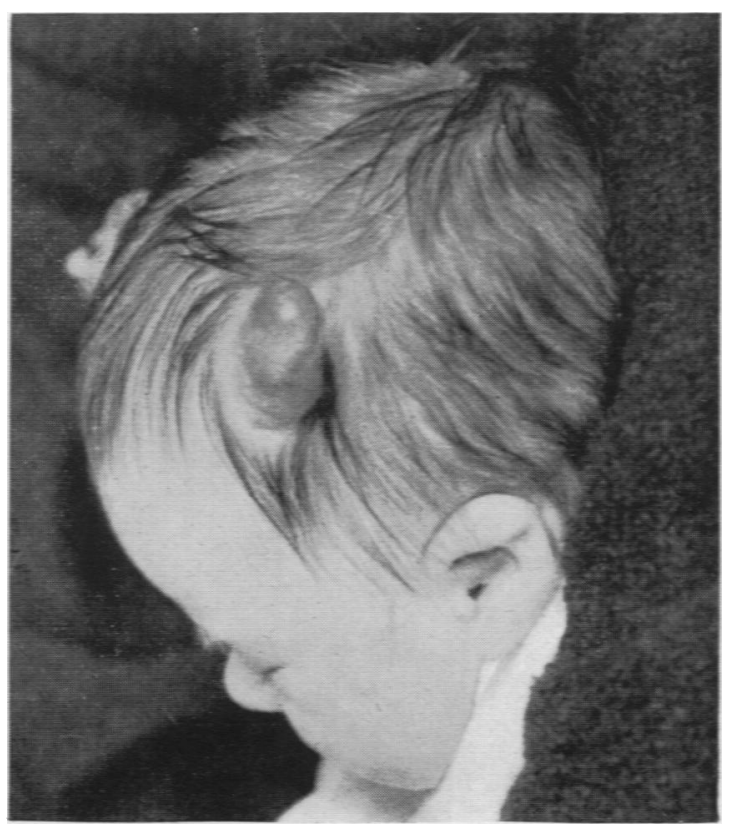

CONGENITAL INTERRUPTION OF THE AORTIC ARCH BY MARGARET SEWART

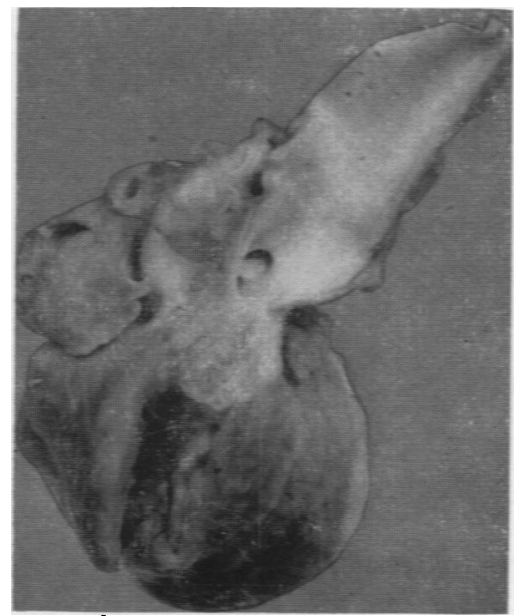

Photograph of the mounted specimen.

Plate II 